\title{
A Study on the Relationship Between Land Finance and Housing Price in Urbanization Process: An Empirical Analysis of 182 Cities in China Based on Threshold Panel Models
}

\author{
Meiting HU \\ School of Economics and Management, University of Chinese Academy of Sciences, Beijing 100190, \\ China \\ E-mail: humeiting18@mails.ucas.ac.cn \\ Jichang DONG \\ School of Economics and Management, University of Chinese Academy of Sciences, Beijing 100190, \\ China \\ E-mail: jcdonglc@ucas.ac.cn \\ Lijun YIN \\ School of Economics and Management, University of Chinese Academy of Sciences, Beijing 100190, \\ China \\ E-mail: yinlijun16@mails.ucas.ac.cn \\ Chun MENG \\ Development Research Centre of the State Council, Beijing 100010, China \\ E-mail: meng.bj@126.com \\ Xiuting LI \\ School of Economics and Management, University of Chinese Academy of Sciences, Beijing 100190, \\ China \\ E-mail: lindaall@163.com
}

\begin{abstract}
Scholars have a variety of theoretical explanations for housing price growth. However, few scholars have studied the internal influence mechanism among urbanization, land finance, and housing price. Based on the data of 182 prefecture-level cities from 2009 to 2016, this paper studies the influence of land finance on housing price under different urbanization rate levels. The study finds that with the increase of urbanization rate, the effect of land finance on housing price presents a "U" shape. Specifically, an increase in land finance by $1 \%$ results in a corresponding increase in average housing price by $0.18 \%$, with relatively low urbanization rate, $0.06 \%$ with medium level of urbanization rate, and $0.38 \%$ with high level of urbanization rate.
\end{abstract}

Keywords urbanization; land finance; housing price; threshold panel model

Received September 28, 2020, accepted December 19, 2020

Supported by Natural Science Foundation of China (71850014, 71532013, 71573244, 71974180) 


\section{Introduction}

Since the 21st century, China has seen rapid economic development and urbanization, with the urbanization rate increasing from $35 \%$ in 1999 to $60 \%$ in 2019. In 20 years, the urbanization rate has nearly doubled (Figure 1). Glaeser and Gottlieb ${ }^{[1]}$ believed that the spatial effect and scale effect demonstrated by cities and the constant urban agglomerations played a leading role in promoting China's economic progress as well as creating a great deal of "urban wealth". Zhao ${ }^{[2]}$ pointed out that the key system for the implementation of urbanization in China was land finance. China's housing market reform in 1998 stimulated the growth of land transfer and provided financial support for urban development. In 1999, land transfer fees reached 50 billion yuan, and in 2018, it reached 6510 billion yuan, accounting for $66.50 \%$ of local government revenue and $7.23 \%$ of China's total GDP. The total is nearly 130 times that of 1999 . Drawing from land finance and housing price trends from 1999 to 2018 (Figure 2), we observe that urbanization rate and housing price are on the rise. In China's real estate market, the housing price includes the capitalized urban value, and the housing price increases with the improvement of urban living quality and increase in residents' income level ${ }^{[3]}$. Chen and $\mathrm{Zhu}^{[4]}$ used the cointegration test to analyze the data of housing price and urbanization level in China from 1991 to 2005 and found that the relationship between them was a positive change and long-term stability. Xie and Huang ${ }^{[5]}$ studied the relationship between housing price and urbanization rate from the perspective of real estate supply and demand. They believed that the increase of urbanization rate would promote the prosperity of real estate-related industries and the rise of housing price. Other scholars posit that with the promotion of new urbanization and the improvement of the quality of urbanization development, the property of "life necessities" of real estate will return, which will help curb the excessive rise of housing price and make it return to a reasonable level ${ }^{[6]}$. Scholars have also performed several studies on the relationship between housing price and land finance. An and Dou ${ }^{[7]}$ proposed that the growth of land fiscal scale would accelerate the rise of housing price, which could solve the land financial problems to achieve the real estate market regulation effect. Wang and Gao ${ }^{[8]}$ pointed out that rise of housing prices would have an effect on land finance. Wang, et al. ${ }^{[9]}$ considered the consumption gap between urban and rural areas as the entry point to study land finance and housing price and found that there was a positive relationship between them. Some scholars have found that when there is rapid growth of land transfer income, the urban housing market expanded rapidly and the housing price increased. The supply of residential land by the local government, housing development supply, and housing sales are significantly correlated with the housing price ${ }^{[10]}$. Based on the data (Figure 2), we observe that land finance rises in a volatile manner, but the housing price rises continuously, so the relationship between the housing price and the land finance may be a type of nonlinear relationship, which may be related to the level stage of urbanization. Based on this economic background and existing theoretical analysis, this paper adopts a threshold panel regression model to study the nonlinear relationship among housing price, land finance, and urbanization, under different urbanization stages, in order to determine heterogeneity in land finance's effect on the housing price. Taking urbanization rate as the threshold variable, this paper performs an empirical study on the relationship between land finance and housing price using the panel threshold regression model. 


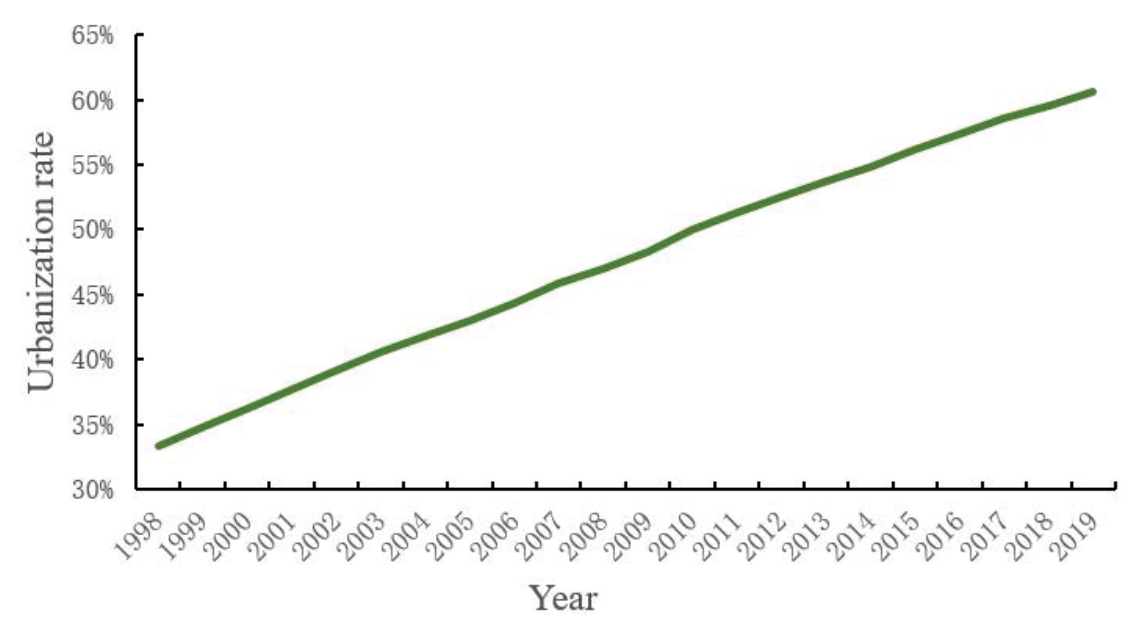

Figure 1 China's urbanization rate from 1999 to 2019

(Data source: iFind database)

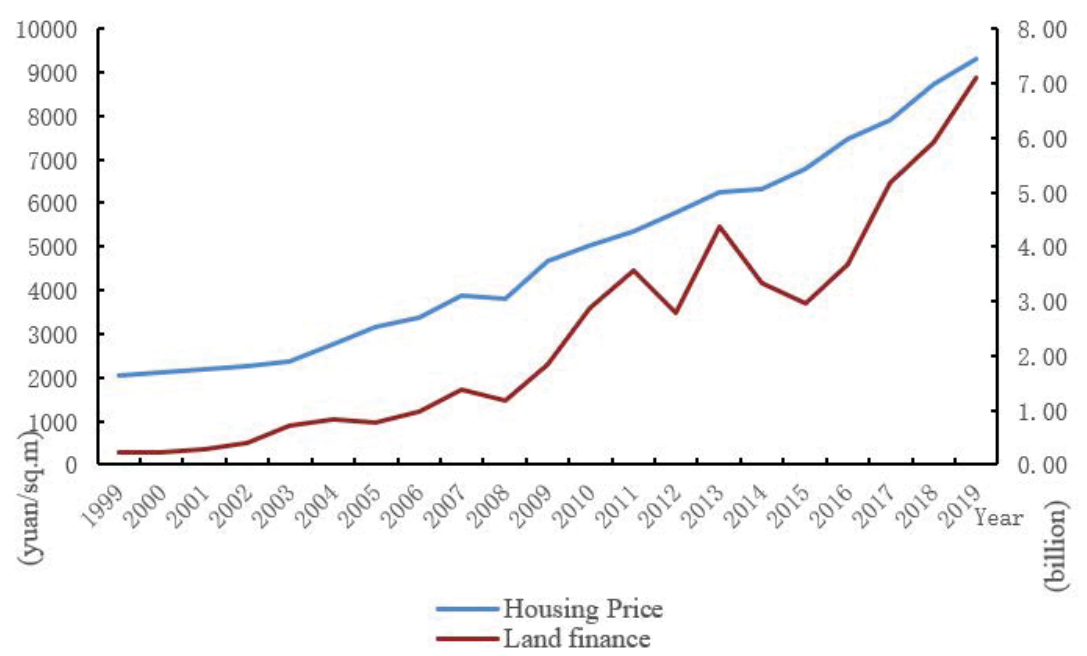

Figure 2 Land finance and housing price from 1999 to 2019

(Data source: Wind database)

The innovations of this paper are as follows. First, in the empirical study of the influence factors of land finance on real estate prices, the moderating variable of urbanization rate was added to empirically test the influence degree of land finance on real estate price under different urbanization rate levels. Second, three models - Granger causality test, general panel regression, and threshold panel regression - were used to empirically test the relationship among urbanization, land finance, and housing price; the urbanization rate was set as the threshold variable and the specific value was obtained. Third, based on the empirical results, this paper proposes policy suggestions for the government to implement land fiscal regulation and housing price regulation at different urbanization levels, enabling the government to carry out land management and real estate regulation policies more reasonably. 


\section{Theoretical Analysis}

\subsection{Complex Causal Relationship Between Urbanization Rate and Land Finance and Housing Price}

Urbanization is the direction for the development of human civilization. It is the most effective way to break the urban-rural dual structure, develop urban and rural economy, and promote the harmonious coexistence of man and nature ${ }^{[11]}$. Urbanization includes population and land, two major factors of production, and the coordinated development between them is a prerequisite for promoting industrial development and enhancing agglomeration effect. China has implemented a series of political and economic reforms, including the tax-sharing system reform in 1994, the establishment of the land reserve system in 1997, the privatization of the housing system in 1998, and the implementation of the land "Bid Invitation, Auction and Listing" system in 2003, which have continuously promoted the improvement of the "land finance model" with Chinese characteristics, the rapid accumulation of raw capital for urban construction, the continued expansion of the old urban space, and the rapid rise of new cities. Domestic and foreign scholars have conducted several studies on the relationship between urbanization, land finance, and housing price. Such studies analyze the causal relationship between urbanization level and housing price from an empirical perspective, and most scholars believe that the reason for rising housing prices is the improvement of urbanization level. Wang and Zhou ${ }^{[2]}$ studied the direct and indirect effects of urbanization on housing prices and believed that the rapid urbanization in the past decade is an important driving factor for the increase in real estate prices. Additionally, Wang and Zhou believed that the acceleration of urbanization would cause an increase in local housing prices, including prices in relevant regions. Many scholars believe that the rigid housing demand caused by large-scale migration of rural population to urban areas will lead to increase in housing prices ${ }^{[13,14]}$. Wang's ${ }^{[15]}$ study found the main factor affecting the real estate price was still the rigid demand formed by population growth and resident income growth. Wang ${ }^{[16]}$ analyzed the relationship between urbanization level and housing price using provincial panel economic data from 2007 to 2016, confirming that urbanization level has a promoting effect on housing price. Other scholars focus on the financial gap of local governments, dependence on land transfer fees, and the interaction between real estate prices. Guo ${ }^{[17]}$ pointed out that the Granger cause of the increase in real estate price was the increase in land finance. On the contrary, using the data of Beijing, Shanghai, Tianjin, and Chongqing municipalities, the empirical study of $\mathrm{Du}$, et al. ${ }^{[18]}$ found that the Granger causality caused by the land price was not established. $\mathrm{Li}$ and $\mathrm{He}^{[19]}$ pointed out that there is a significant positive interaction between housing price rise, local government land financial incentive, and urbanization level. $\mathrm{Li}$ and $\mathrm{Pan}{ }^{[20]}$ studied the relationship among soil urbanization, land finance, and real estate development by establishing the simultaneous equation model of panel data. Results show that land finance significantly negatively regulated the urbanization process; however, urbanization actively promoted the development of real estate and land finance. Some scholars concluded that during economic transformation and development in China, the "land requisition-land supply" mode initiated by local governments led to the increase of land price to expand their own financial resources, resulting in the preference for social resources over real estate and the skyrocketing of housing prices ${ }^{[21]}$. Based on the above analysis, the 
first hypothesis is proposed:

H1 There is a complex causal relationship between urbanization rate and land finance and housing price.

\subsection{Influence of Land Finance on Housing Price Moderated by Urbanization Rate}

Many scholars have performed a great deal of research on the relationship between housing price and land finance, and most of them point out that there is a significant positive correlation between the two. Since the reform of the tax sharing system, local governments have been burdened with additional financial burdens. Local governments have gradually relied on land revenue and the development of the real estate industry to alleviate the contradiction between fiscal revenue and expenditure. The rise of housing prices further promoted the prosperity of the real estate market, and then superimposed the development of land finance. Shen and $\mathrm{Liu}^{[22]}$ studied the relationship between economic fundamentals and housing prices, pointing out that an increase of $10 \%$ of the total urban population will lead to an increase of $2 \%$ of urban housing prices. Ren and Liu ${ }^{[23]}$ studied the dynamic economic model of housing price and urbanization, demonstrating that rapid urbanization will lead to a rapid rise of housing price as well as the improvement of urbanization rate will also have a positive impact on housing price. Luo ${ }^{[24]}$ confirmed this conclusion using different economic models. The improvement of urbanization level can significantly promote the real estate prices in surrounding areas. Other scholars analyzed land finance and housing price through economic theoretical model and found that they are mutually influencing and promoting each other ${ }^{[25]}$. Han and Wang ${ }^{[26]}$ studied the relationship between urbanization and real estate prices from the perspective of urban-rural income gap. Based on China's provincial panel data from 1999 to 2010, the study shows that urbanization only affects $2 \%$ of the rise in real estate prices, which is not a significant impact. $\mathrm{Yin}^{[27]}$ posited that the factors affecting the housing price of the main cities and sub-cities have spatial heterogeneity. Among them, the main city is considerably affected by the distance from the central business district (CBD), the age of residential buildings, and the greening rate, whereas the secondary city is substantially affected by the distance from subway stations and the distance from landscape resources. Wu, et al. ${ }^{[28]}$ analyzed the supply and demand data of major cities in China and believed that the increase of housing price was different among different regions, but the common reason for the increase of housing price was the increase of land price. Nathanson and Zwick ${ }^{[29]}$ suggested that speculation in the land market is easier than that in the real estate market. The undeveloped land is conducive to construction and promotes the speculation behavior, thus resulting in intense fluctuations in the housing price. Using the multiple sector economic model, Garriga and Hedlund ${ }^{[30]}$ found that urbanization is the driving force behind the housing price plateau, which explains $80 \%$ of the changes in urban housing price. Gong ${ }^{[31]}$ studied the effect mechanism of urbanization on housing price from the perspective of urbanization decomposition. According to the panel data of 273 cities in China from 2006 to 2015, the rise of urbanization level increases the housing price. Based on the above analysis, the second hypothesis is proposed.

H2 The impact of land finance on the fluctuation of housing price is regulated by the urbanization rate. 


\subsection{Threshold Effect on the Impact of Land Finance on the Fluctuation of Housing Price and a U-Shaped Relationship Between Urbanization Rate and Housing Price}

Land finance is the financial foundation of urbanization and industrialization in China in the past decades. The rapid expansion of government finance is closely related to the landcentered urbanization process. Studies by numerous scholars at home and abroad demonstrate that the advancement of urbanization promotes the rise of housing prices through a variety of ways. Some scholars studied the impact of land use control on real estate prices in the United States, and found that more and more artificial restrictions led to a shortage of land for housing construction, which led to a rise in housing prices ${ }^{[32,33]}$. Zhu ${ }^{[34]}$ considering the speed and stage of urbanization development as the entry point, analyzed the transmission mechanism of rapid urbanization, which is responsible for the rise of housing price. Many domestic scholars have studied the influence of urbanization rate on housing price from the aspects of land policy, land supply structure, land supply model ${ }^{[35,36]}$. Land finance benefits real estate developers, local government finance, and homebuyers motivated by investment needs ${ }^{[37]}$. Tang and $\mathrm{Wu}^{[38]}$ analyzed the economic data of 15 large and medium-sized cities in China from 2009 to 2015, and demonstrated that local governments rely on land transfer fees and other related income, thus promoting the impact of land finance on the rise of housing prices. At the same time, the behavior of real estate enterprises, to a certain extent, amplifies the impact of land finance on the high housing prices. Additionally, some scholars hold the view that land finance did not push up the housing price, and there was no significant correlation between the two. The main factors that pushed up the housing price were the performance appraisal mechanism based on GDP and other factors. The rise in housing prices cannot be attributed to land finance ${ }^{[39-41]}$.

Based on the aforementioned theoretical analysis, we believe that there are two key factors worth considering in the analysis of the causes of changes in housing prices: Land finance and urbanization. The importance of land finance to local governments has become increasingly evident, which is an important means of local fiscal revenue. The housing price continues to rise, as the process of local governments continues to expand land-related income and maintain the prosperity of the real estate market. Urbanization is the outcome of rapid economic development, which promotes the expansion of urban population scale and the upgrading of industrial structure, and this, in turn, helps the development of real estate industry and drives the rise of housing price. Land finance will affect the level of housing price, but there are disputes regarding the direction of influence in existing studies. The reason for the dispute may be that the effect of land finance on housing price is different at different urbanization levels; however, previous studies did not consider this difference, so we propose:

H3 There may be a threshold effect on the effect of land finance on the housing price, and the adjustment relationship between urbanization rate and the housing price is U-shaped.

\subsection{Influence Mechanism of Land Finance on Housing Price in the Process of Urbanization}

Since the reform and opening up, China's urbanization process has been accelerating. During the 40-plus years, from the reform and opening up to 2019, China's urban population 
increased from 185 million to 84.8 million (National Bureau of Statistics), nearly quadrupling the urban population and pushing the country's urbanization rate to more than $60 \%$ in 2019 . From the perspective of the three development stages of Northam's urbanization, China is currently in the second stage of medium-high-speed development (Figure 3).

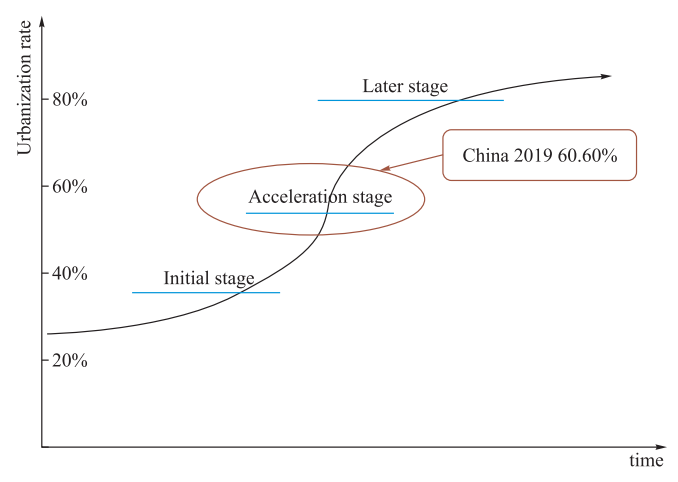

Figure 3 Development stages of urbanization in the world (Data Source: Collected by the authors)

In the process of promoting local urbanization, the behavior motive and logic of local government are complicated, which are influenced by both incentive factors and external system. Although this paper does not discuss the concrete behavior of the government, it focuses on the analysis of economic logic. The government aims to maximize people's welfare. In the short term, measures such as increasing public expenditure can improve the overall level of social security of all residents, while in the long term, welfare can only be maximized by improving the level of economic development. One of the main components of economic growth is urbanization. Therefore, to improve both the long-term and short-term welfare levels, the government should not only increase public fiscal expenditure, but also accelerate the development of urbanization. Urbanization requires land, and local governments have a monopoly on land, which empowers governments to sell land in order to generate revenue for fiscal expenditure. In the stage of rapid urbanization development, the rapid expansion of urbanization scale is bound to occupy a large amount of land resources, that is, the urbanization process is inseparable from the input of land factors. Due to the tax distribution reform, the financial pressure of local governments is constantly increasing. In order to maintain the balance of local financial revenue and expenditure, local governments gradually take the path of land finance, which makes local finance more dependent on the real estate industry, directly raising the real estate price and indirectly guiding the expectation of the real estate market. The improvement of the urbanization rate has an impact on the housing price mainly through the following three ways: First, the acceleration of urbanization leads to the rapid growth of urban population. Coupled with the reform of the household registration system, it considerably stimulates the housing demand of urban population, thus pushing up the housing price. Second, the acceleration of urban industrialization leads to the shortage of land resources and pushes up the cost of housing development. Finally, the industrial structure has been constantly transformed and upgraded in recent years. The proportion of the secondary and tertiary industries is constantly expanding. 
The linkage between industries and the continuous improvement of urban infrastructure drives the development of real estate-related industries and promotes the rise of housing prices.

This paper constructs the mechanism path chart of the impact of land finance on housing price in the process of urbanization and uses the threshold panel regression model to study the relationship among land finance, urbanization, and housing price: Can land finance influence estate price? If so, will the urbanization level have a moderating effect on this influence mechanism? Through the construction of the influence mechanism road map and the threshold panel regression model (see Figure 4), we hope to make a more intuitive interpretation of the economic implications behind the proposition given in this paper.

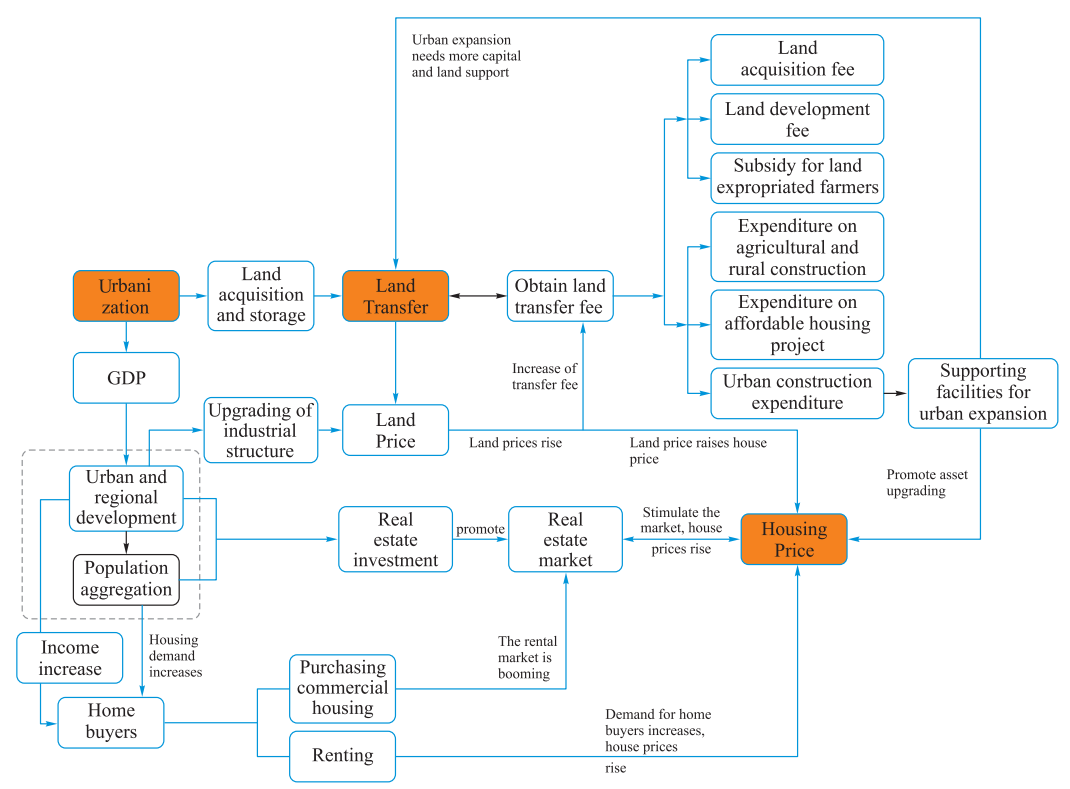

Figure 4 Mechanism path chart of the interaction between urbanization, land finance, and housing price

(Data Source: Collected by the authors)

\section{Data and Methodology}

\subsection{Variable Selection and Data Sources}

In order to examine the causal relationship between urbanization, housing price, and land transfer fee in the Granger causality study, we used national data (1999-2018), because the time span of prefecture-level city data (2009-2016) is relatively short. The variables in the general panel regression model and threshold panel regression model are based on the panel data of 182 large and medium-sized cities in China from 2009 to 2016. Land finance is measured by land transfer fee, housing price is measured by the ratio of commercial housing sales to commercial housing sales area, and urbanization rate is measured by the ratio of the permanent urban population to the permanent urban population of the city.

In addition to local financial factors, local GDP, supply and demand of commercial housing, urbanization rate, industrial structure, public facilities, and other factors will also influence the price level of commercial housing. This research selects control variables from the above- 
mentioned aspects. Foremost, the level of local economic development and the average income of employees are closely related to the housing price, so we include the average salary of employees and GDP as the control variables. As housing demand is directly related to regional population density, we choose population density index to control commercial housing demand. In addition, due to the close relationship between real estate development investment and commercial housing supply, we select the real estate development investment as a variable to control the impact of commercial housing supply on the housing price. According to existing literature, urban industrial structure and average road area also have a certain impact on the real estate price, so two control variables were added: The proportion of tertiary industry and per average road paving area. Descriptive statistics of variables at the national and province level are shown in Tables 1 and 2.

Table 1 Descriptive statistics of variables at the country level

\begin{tabular}{ccccccc}
\hline Variable & Symbol & $\begin{array}{c}\text { Observed } \\
\text { value }\end{array}$ & $\begin{array}{c}\text { Mean } \\
\text { value }\end{array}$ & $\begin{array}{c}\text { Standard } \\
\text { deviation }\end{array}$ & $\begin{array}{c}\text { Minimum } \\
\text { Value }\end{array}$ & $\begin{array}{c}\text { Maximum } \\
\text { Value }\end{array}$ \\
\hline $\begin{array}{c}\text { Land transfer fee } \\
(100 \text { million yuan) }\end{array}$ & ltf & 20 & 2.06 & 1.85 & 0.05 & 6.51 \\
$\begin{array}{c}\text { Urbanization rate } \\
\text { Housing price } \\
\text { (yuan/sq.m) }\end{array}$ & ur & 20 & 0.477 & 0.08 & 0.35 & 0.60 \\
\hline
\end{tabular}

Table 2 Descriptive statistics of variables at prefecture-level cities

\begin{tabular}{|c|c|c|c|c|c|c|}
\hline Variable & Symbol & $\begin{array}{l}\text { Observed } \\
\text { value }\end{array}$ & Average & $\begin{array}{l}\text { Standard } \\
\text { deviation }\end{array}$ & $\begin{array}{l}\text { Minimum } \\
\text { Value }\end{array}$ & $\begin{array}{l}\text { Maximum } \\
\text { Value }\end{array}$ \\
\hline $\begin{array}{l}\text { Gross National Product } \\
\text { (100 million yuan) }\end{array}$ & gdp & 1456 & 2702.03 & 3253.54 & 120.67 & 28178.70 \\
\hline $\begin{array}{l}\text { The proportion of tertiary } \\
\text { industry }\end{array}$ & $\mathrm{ti}$ & 1456 & 0.40 & 0.10 & 0.14 & 0.80 \\
\hline Housing price (yuan/sq.m) & $\mathrm{hp}$ & 1456 & 5397.60 & 3501.09 & 396.00 & 45146.00 \\
\hline $\begin{array}{l}\text { Land transfer fee }(10,000 \\
\text { yuan })\end{array}$ & $\operatorname{ltf}$ & 1456 & 1230000.00 & 2390000.00 & 55.00 & $1.98 \times 10^{7}$ \\
\hline Urbanization rate & ur & 1456 & 0.52 & 0.16 & 0.08 & 1.00 \\
\hline $\begin{array}{l}\text { Population density } \\
\quad\left(\text { person } / \mathrm{km}^{2}\right)\end{array}$ & pld & 1456 & 1094.47 & 919.43 & 86.69 & 11449.30 \\
\hline $\begin{array}{l}\text { Completed amount of real } \\
\text { estate development } \\
\text { investment ( } 10,000 \text { yuan })\end{array}$ & inv & 1456 & 2740000.00 & 4940000.00 & 24352.00 & $4.24 \times 10^{7}$ \\
\hline $\begin{array}{c}\text { Road paving area per } \\
\text { average }(\mathrm{m})\end{array}$ & road & 1456 & 13.71 & 30.00 & 1.62 & 1117.97 \\
\hline $\begin{array}{c}\text { Average salary level of } \\
\text { employees (yuan) }\end{array}$ & wage & 1456 & 47394.76 & 14611.19 & 12721.22 & 123000.00 \\
\hline
\end{tabular}




\subsection{Model Specification}

\subsubsection{Granger Causality Test Model for Panel Data}

Granger causality test refers to the method of Hoffmann ${ }^{[42]}$. The urbanization rate is represented by ur, hp is the housing price, and ltf stands for land transfer fee, then the unconstrained regression model between urbanization rate and housing price and land transfer fee can be expressed as:

$$
\begin{aligned}
& \operatorname{ur}_{i, t}=\alpha_{i 1}+\sum_{k=1}^{p} \gamma_{i 1}^{(k)} \operatorname{ur}_{i, t-k}+\sum_{k=1}^{p} \beta_{i 1}^{(k)} \operatorname{ltf}_{i, t-k}+\varepsilon_{i, t}, \\
& \operatorname{ltf}_{i, t}=\alpha_{i 2}+\sum_{k=1}^{p} \gamma_{i 2}^{(k)} \operatorname{ltf}_{i, t-k}+\sum_{k=1}^{p} \beta_{i 2}^{(k)} \operatorname{ur}_{i, t-k}+\vartheta_{i, t} .
\end{aligned}
$$

In Equations (1) and (2), $i=1,2, \cdots, N, t=1,2, \cdots, T, \alpha_{i 0}$ and $\alpha_{i 1}$ are the intercept term; $\varepsilon_{i, t}$ and $\vartheta_{i, t}$ are independently and identically distributed and obey normal distribution; the mean value is 0 , variance is $\sigma^{2}$. If the coefficient $\beta_{i 0}^{(k)}$ is not all 0 , then land finance is the Granger cause of urbanization rate. If $\beta_{i 1}^{(k)}$ is not all 0 , it shows that urbanization rate is the Granger cause of land finance. If $\beta_{i 1}^{(k)}$ and $\beta_{i 1}^{(k)}$ are both not 0 , it shows that there is a mutual feedback effect between land finance and urbanization rate.

Similarly, the unconstrained regression model between real estate price and urbanization rate can be expressed as:

$$
\begin{aligned}
\operatorname{ur}_{i, t} & =\alpha_{i 3}+\sum_{k=1}^{p} \gamma_{i 3}^{(k)} \operatorname{ur}_{i, t-k}+\sum_{k=1}^{p} \beta_{i 3}^{(k)} \mathrm{hp}_{i, t-k}+\varepsilon_{i, t}, \\
\mathrm{hp}_{i, t} & =\alpha_{i 4}+\sum_{k=1}^{p} \gamma_{i 4}^{(k)} \mathrm{hp}_{i, t-k}+\sum_{k=1}^{p} \beta_{i 4}^{(k)} \mathrm{ur}_{i, t-k}+\vartheta_{i, t} .
\end{aligned}
$$

The unconstrained regression model between land transfer fee and housing price can be expressed as:

$$
\begin{aligned}
& \operatorname{ltf}_{i, t}=\alpha_{i 5}+\sum_{k=1}^{p} \gamma_{i 5}^{(k)} \operatorname{ltf}_{i, t-k}+\sum_{k=1}^{p} \beta_{i 5}^{(k)} \mathrm{hp}_{i, t-k}+\varepsilon_{i, t} \\
& \mathrm{hp}_{i, t}=\alpha_{i 6}+\sum_{k=1}^{p} \gamma_{i 6}^{(k)} \mathrm{hp}_{i, t-k}+\sum_{k=1}^{p} \beta_{i 6}^{(k)} \operatorname{ltf}_{i, t-k}+\vartheta_{i, t} .
\end{aligned}
$$

\subsubsection{Common Panel Regression and Panel Threshold Model}

In order to verify the role of urbanization in the impact of land finance on housing price, this paper first adopts the ordinary panel regression model for empirical test. The interactive variable of urbanization and land finance was added into the model. Second, based on the aforementioned theoretical analysis, there may be a threshold effect on the impact of land finance on the housing price. Threshold effect refers to the grouping of sample data through threshold variables. The influence of independent variables on dependent variables is different in different threshold ranges, and then the threshold panel regression model is used to study the threshold effect of urbanization. 
The normal panel regression model is set as:

$$
\begin{array}{r}
\operatorname{hp}_{i t}=\beta_{0}+\beta_{1} * \operatorname{ltf}_{i t}+\beta_{2} * \operatorname{ur}_{i t}+\beta_{3} * x_{i t}+\sigma_{t}+\varepsilon_{i t}, \\
i=1,2, \cdots, n, \quad t=1,2, \cdots, t,
\end{array}
$$

where $\mathrm{hp}_{i t}$ is the explained variable representing the change of housing price; $\operatorname{ltf}_{i t}$ is the variable reflecting the fiscal level of land in each region and $u_{i t}$ reflects the urbanization level; $x_{i t}$ represents the remaining control variables; $\sigma_{t}$ is the time fixed effect; and $\varepsilon_{i t}$ stands for independent identically distributed random error term, variance is 1 , and the mean value is 0 .

The panel regression model for adding the interaction items is set as follows:

$$
\begin{array}{r}
\operatorname{hp}_{i t}=\beta_{0}+\beta_{1} * \operatorname{ltf}_{i t}+\beta_{2} * \operatorname{ur}_{i t}+\beta_{3} * \operatorname{ur}_{i t} * \operatorname{ltf}_{i t}+\beta_{4} * x_{i t}+\sigma_{t}+\varepsilon_{i t}, \\
i=1,2, \cdots, n, \quad t=1,2, \cdots, t
\end{array}
$$

The panel threshold model with a single threshold is set as follows:

$$
\begin{array}{r}
\operatorname{hp}_{i t}=\alpha_{0}+\alpha_{1} * \operatorname{ltf}_{i t} * \mathrm{I}\left(\operatorname{ur}_{i t}<c\right)+\alpha_{2} * \operatorname{ur}_{i t} * \mathrm{I}\left(\operatorname{ur}_{i t}>c\right)+\alpha_{3} * x_{i t}+\sigma_{t}+\varepsilon_{i t} \\
i=1,2, \cdots, n, \quad t=1,2, \cdots, t
\end{array}
$$

Based on existing studies, the urbanization level does not necessarily show a single threshold effect. When there is a two-door limit, the model is set as follows:

$$
\begin{aligned}
y_{i t}= & \alpha_{0}+\alpha_{1} * \operatorname{ltf}_{i t} * \mathrm{I}\left(\operatorname{ur}_{i t}<c_{1}\right)+\alpha_{2} * \operatorname{ur}_{i t} * \mathrm{I}\left(c_{1} \leq \operatorname{ur}_{i t} \leq c_{2}\right) \\
& +\alpha_{3} * \operatorname{ur}_{i t} * \mathrm{I}\left(\operatorname{ur}_{i t}>c_{2}\right)+\alpha_{4} * x_{i t}+\sigma_{t}+\varepsilon_{i t}
\end{aligned}
$$

\subsection{Data Sources and Processing}

Many scholars use provincial data or data of more than 30 large and medium-sized cities in similar empirical studies. Considering that municipal and local governments are the subject of land transfer behavior, the economic status and the degree of land finance dependence among cities in the same province are different. These differences would be ignored if provincial data were used. However, 35 large and medium-sized cities can only represent the basic situation of China's large and medium-sized cities and cannot show the situation of other levels of development of China's cities that has certain limitations. Based on this, this study selects panel data from 182 prefecture-level cities in China for an empirical test. Considering the data availability of various variables, the time span is 2009-2016.

Housing price (hp), gross domestic product (GDP), proportion of tertiary industry (ti), average wage of employees (wage), and total investment in real estate development (inv) are from the Wind database, supplementing the missing data by inquiring China Regional Statistical Yearbook (2008-2016). The data of land transfer fee and urbanization rate can be obtained through iFind database. Some missing values were supplemented by inquiring China Regional Statistical Yearbook (2008-2016). Population density and pavement area average were obtained by inquiring China Urban Statistics Yearbook (2008-2016). Due to missing data in the selected data, interpolation method or web search method is used to obtain the missing data. 


\section{Empirical Results}

\subsection{Unit Root Test}

First, the stable test is conducted on the sample data. D-F unit root test was used to test the stable of data in order to avoid false regression and making regression results more effective. The test results are shown in Table 3 .

Table 3 Unit root test of panel data of 182 prefecture-level cities from 2009 to 2016

\begin{tabular}{|c|c|c|c|c|}
\hline Variable & Symbol & Coefficient & $T$ value & $P$ value \\
\hline Housing price (yuan/sq.m) & $\mathrm{hp}$ & -0.35267 & -10.848 & 0.0010 \\
\hline Land transfer fee (ten thousand yuan) & $\operatorname{ltf}$ & -0.50668 & -16.951 & 0.0000 \\
\hline Urbanization rate & ur & -0.55719 & -31.315 & 0.0000 \\
\hline Gross National Product (100 million yuan) & $\operatorname{gdp}$ & -0.11208 & -20.011 & 0.0000 \\
\hline Proportion of tertiary industry & $\mathrm{ti}$ & -0.38449 & -23.701 & 0.0000 \\
\hline Average salary level of employees (yuan) & wage & -0.23517 & -11.997 & 0.0000 \\
\hline Population density (person $/ \mathrm{km}^{2}$ ) & pld & -0.10485 & -4.215 & 0.0010 \\
\hline $\begin{array}{l}\text { Completed amount of estate development } \\
\text { investment (ten thousand yuan) }\end{array}$ & inv & -0.10431 & -6.312 & 0.0305 \\
\hline Road paving per capita area (m) & road & -1.60143 & -58.482 & 0.0000 \\
\hline
\end{tabular}

As the results in Table 3 demonstrate, the $P$ values of all variables are significant, so all variables are stationary series.

\subsection{Granger Causality Test}

First, the data of land transfer fee and urbanization rate are standardized. According to DF test, $Z_{(t)}$ value is 0.0076 and 0.0339 , respectively, which shows that both land finance and urbanization rate are first-order integration series and there is no co-integration relationship, so the sample data are suitable for Granger causality test. The test results are shown in Table 4.

Table 4 Granger causality test results

\begin{tabular}{ccc}
\hline Granger null hypothesis of causality & $F$ statistic & $\begin{array}{c}\text { Accept/Reject the null } \\
\text { hypothesis }\end{array}$ \\
\hline Land finance is not the Granger reason for urbanization & 2.13 & accept \\
Urbanization is not the Granger reason for land finance & 3.57 & accept \\
Housing prices are not the Granger reason for urbanization & 0.13 & reject \\
Urbanization is not the Granger reason for housing prices & 3.08 & . \\
\hline
\end{tabular}

Table 4 shows that urbanization in China is the Granger cause of land finance and housing price, indicating that urbanization has an impact on both land finance and housing price. The relationship between commodity housing price and land finance cannot be easily determined. Urbanization possibly plays an important role in co-integration between the two, which needs further in-depth study. Hypothesis 1 can be verified: Urbanization level has a complex causal relationship with land finance and housing price. 


\subsection{Normal Panel Model Regression}

To test land finance (ltf) effect on real estate price (hp), the ordinary panel data model is first adopted. We take housing price (hp) as the explained variable and land finance and urbanization level as the main explanatory variables for comparative analysis, as shown in Table 5 .

Table 5 Normal panel regression results

\begin{tabular}{|c|c|c|c|c|c|}
\hline Variable & Symbol & Model 1 & Model 2 & Model 3 & Model 4 \\
\hline Land transfer fee & $\operatorname{ltf}$ & $\begin{array}{c}0.1466^{* * *} \\
(0.0267)\end{array}$ & $\begin{array}{c}0.1445^{* * *} \\
(0.0268)\end{array}$ & $\begin{array}{c}-0.0646^{*} \\
(0.0439)\end{array}$ & $\begin{array}{c}-0.1220^{* * *} \\
(0.0460)\end{array}$ \\
\hline Gross National Product & gdp & $\begin{array}{c}0.5999 * * * \\
(0.0497)\end{array}$ & $\begin{array}{c}0.5804^{* * *} \\
(0.0500)\end{array}$ & $\begin{array}{c}0.5331^{* * *} \\
(0.0505)\end{array}$ & $\begin{array}{c}0.4705^{* * *} \\
(0.0516)\end{array}$ \\
\hline Proportion of tertiary industry & $\mathrm{ti}$ & $\begin{array}{c}0.0945^{* * *} \\
(0.0296)\end{array}$ & $\begin{array}{c}0.0889^{* * *} \\
(0.0305)\end{array}$ & $\begin{array}{c}0.1007^{* * *} \\
(0.0294)\end{array}$ & $\begin{array}{c}0.0776^{* * *} \\
(0.0300)\end{array}$ \\
\hline Average wage of employees & wage & $\begin{array}{c}0.1737^{* * *} \\
(0.0172)\end{array}$ & $\begin{array}{c}0.1651^{* * *} \\
(0.0180)\end{array}$ & $\begin{array}{c}0.1968^{* * *} \\
(0.0174)\end{array}$ & $\begin{array}{c}0.1780^{* * *} \\
(0.0178)\end{array}$ \\
\hline Population density & pld & $\begin{array}{l}-0.0244 \\
(0.0216)\end{array}$ & $\begin{array}{l}-0.0276 \\
(0.0216)\end{array}$ & $\begin{array}{l}-0.0227 \\
(0.0214)\end{array}$ & $\begin{array}{l}-0.0289 \\
(0.0212)\end{array}$ \\
\hline Investment in real estate development & inv & $\begin{array}{c}-0.1794^{* *} \\
(0.0384)\end{array}$ & $\begin{array}{c}-0.1717^{* * * *} \\
(0.0386)\end{array}$ & $\begin{array}{c}-0.1785^{* * *} \\
(0.0380)\end{array}$ & $\begin{array}{c}-0.1561^{* * *} \\
(0.0380)\end{array}$ \\
\hline Pavement area per capita & road & $\begin{array}{c}0.0047 \\
(0.0107)\end{array}$ & $\begin{array}{c}0.0045 \\
(0.0108)\end{array}$ & $\begin{array}{c}0.0045 \\
(0.0106)\end{array}$ & $\begin{array}{c}0.0039 \\
(0.0106)\end{array}$ \\
\hline Urbanization rate & ur & & $\begin{array}{c}0.0558 \\
(0.0364)\end{array}$ & & $\begin{array}{c}0.1571^{* * *} \\
(0.0385)\end{array}$ \\
\hline $\begin{array}{l}\text { Interaction item between urbanization } \\
\text { rate and land finance }\end{array}$ & urltf & & & $\begin{array}{c}0.1601^{* * *} \\
(0.0266)\end{array}$ & $\begin{array}{c}0.1998^{* * *} \\
(0.0283)\end{array}$ \\
\hline Return to intercept & _cons & $\begin{array}{c}0.0000 \\
(0.0409)\end{array}$ & $\begin{array}{c}0.0000 \\
(0.0392)\end{array}$ & $\begin{array}{l}-0.0808^{*} \\
(0.0431)\end{array}$ & $\begin{array}{c}-0.1009^{* *} \\
(0.0410)\end{array}$ \\
\hline Sample quantity & $N$ & 1456 & 1456 & 1456 & 1456 \\
\hline$R^{2}$ value & $R^{2}$ & 0.5986 & 0.5934 & 0.5929 & 0.5819 \\
\hline$P$ value & $p$ & 0.0000 & 0.0000 & 0.0000 & 0.0000 \\
\hline
\end{tabular}

Notes: The standard error robust to heteroscedasticity is shown in parentheses; ${ }^{* * *}$, **, and ${ }^{*}$ represent that the estimated coefficients are significant at the 1\%,5\%, and $10 \%$ confidence levels, respectively.

In Table 5, Model 1 does not include the regression results of urbanization rate and interaction item. Model 2 includes the regression results of ur and Model 3 includes the regression results of urltf. Model 4 includes variables of ur and urltf. Table 5 shows that, without adding the cross-term model of urbanization rate and land finance, the impact of land finance on the 
price of commercial housing is significantly positive. The conclusion is consistent with the research of most scholars at present: Land finance has a significant role in promoting housing prices $^{[43,44]}$. Compared with Model 2 after urbanization rate is added, land finance still has a positive and significant impact on housing price. Its coefficient slightly drops. For every $1 \%$ increase in land transfer income, the price of commercial housing will rise by $0.1445 \%$. Control variables are consistent with Model 1. Model 3 adds the variable of interaction between urbanization rate and land finance. It is obvious that land finance has a significant negative impact on the price of commercial housing. The coefficient of the interaction term between urbanization rate and land finance is greater than 0 , which is 0.1601 . This shows that the influence of land finance on housing price changes gradually with the increase of urbanization rate, tending to be more and more positive with the increase of urbanization. Therefore, in the process of urbanization, the impact of land finance on the price of commercial housing is heterogeneous because of different urbanization rates. The threshold effect may exist in the urbanization rate, which verifies Hypothesis 2 proposed in this paper. In Model 4, urbanization and cross terms were added respectively, and the results were similar to Model 3.

In the empirical test, the effect of land finance on the price of commercial housing is significant, whether there is an urbanization rate variable or not. After adding the urbanization rate variable, land finance also has a significant positive effect on the price of commercial housing. However, when the variable of the interaction between urbanization rate and land finance is added, land finance negatively affects the price of commercial housing, indicating that the impact of land finance on the price of commercial housing may be moderated by urbanization. As can be seen from the interaction coefficient, the impact of land fiscal revenue on the price of commercial housing tends to be positive with the improvement of urbanization level. Based on the Granger causality test results, urbanization level is the Granger cause of land finance and housing price; therefore, the impact of land finance on housing price will inevitably be affected by different urbanization rates. Hence, it is necessary to use the threshold panel regression model and take the urbanization rate as the threshold variable to further empirically study the impact of land fiscal scale on housing price.

\subsection{Threshold Panel Model Regression}

Based on the aforementioned theoretical analysis and empirical results, we selected urbanization rate (ur) as the threshold variable. Land finance scale (ltf) is the main explanatory variable. Control variables include GDP, population density (pld), average salary of employees (wage), real estate development investment (inv), and pavement area per capita (road). For data samples with different sample sizes, control variables are added to the tertiary industry proportional variable (ti), secondary industry proportional variables (si), and primary industry proportional variables (fi), Thus, the function of industrial structure on the model as well as the robustness of the model are verified. Due to the complexity of the model, this paper refers to the practice of some scholars to set the threshold value within two.

\subsubsection{Threshold Effect Test}

First, we test the threshold effect of panel data to determine the number of the threshold. Referring Wu's ${ }^{[45]}$ sampling method (Bootstrap program command), we use Stata14.0 statistical 
software and set 1000 repeat samples. The test results of threshold effect are shown in Table 6. As shown in Table 6, there are all two threshold values for the proportion of the primary industry, the proportion of the secondary industry, or the proportion of the tertiary industry.

Table 6 Test results of threshold effect of panel data of 182 prefecture-level cities

\begin{tabular}{ccccccc}
\hline \multirow{2}{*}{ Test hypotheses } & \multicolumn{2}{c}{$\begin{array}{c}\text { Join the primary } \\
\text { industry proportion }\end{array}$} & $\begin{array}{c}\text { Join the secondary } \\
\text { industry proportion }\end{array}$ & \multicolumn{2}{c}{$\begin{array}{c}\text { Join the tertiary } \\
\text { industry proportion }\end{array}$} \\
\cline { 2 - 7 } & $F$ Value & $P$ Value & $F$ Value & $P$ Value & $F$ value & $P$ value \\
\hline $\begin{array}{c}\text { H0: Unable to limit } \\
\text { H1: One threshold value }\end{array}$ & 36.5217 & 0.0000 & 36.4620 & 0.0000 & 36.4595 & 0.0000 \\
$\begin{array}{l}\text { H0: One threshold value } \\
\text { H1: Two threshold values }\end{array}$ & 3.5495 & 0.0640 & 3.5827 & 0.0490 & 3.5801 & 0.0550 \\
\hline
\end{tabular}

\subsubsection{Threshold Model Regression Results}

According to the threshold values given in Table 6, the corresponding parameter estimates of the threshold panel regression model are shown in Table 7 .

Table 7 Regression model results of threshold panel

\begin{tabular}{|c|c|c|c|c|}
\hline Explanatory variables & Symbol & Model 5 & Model 6 & Model 7 \\
\hline Gross National Product & $\operatorname{gdp}$ & $\begin{array}{c}0.6234^{* * *} \\
(0.1761)\end{array}$ & $\begin{array}{c}0.6230^{* * *} \\
(0.1763)\end{array}$ & $\begin{array}{c}0.6231^{* * *} \\
(0.1762)\end{array}$ \\
\hline Proportion of primary industry & fi & $\begin{array}{c}-0.0209^{*} \\
(0.0136)\end{array}$ & & \\
\hline Proportion of secondary industry & si & & $\begin{array}{l}-0.0013 \\
(0.0183)\end{array}$ & \\
\hline Proportion of tertiary industry & $\mathrm{ti}$ & & & $\begin{array}{c}0.0013^{*} \\
(0.0233)\end{array}$ \\
\hline Average wage level of employees & wage & $\begin{array}{c}0.1839 * * * \\
(0.0223)\end{array}$ & $\begin{array}{c}0.1830^{* * *} \\
(0.0216)\end{array}$ & $\begin{array}{c}0.1829 * * * \\
(0.0215)\end{array}$ \\
\hline Population density & pld & $\begin{array}{l}-0.0181 \\
(0.0148)\end{array}$ & $\begin{array}{l}-0.0178 \\
(0.0149)\end{array}$ & $\begin{array}{l}-0.0178 \\
(0.0149)\end{array}$ \\
\hline Investment in estate development & inv & $\begin{array}{c}-0.1681^{*} \\
(0.1064)\end{array}$ & $\begin{array}{c}-0.1676^{*} \\
(0.1064)\end{array}$ & $\begin{array}{c}0.1675^{*} \\
(0.1064)\end{array}$ \\
\hline Pavement area per capita & road & $\begin{array}{c}0.0036^{*} \\
(0.0022)\end{array}$ & $\begin{array}{c}0.0036^{*} \\
(0.0022)\end{array}$ & $\begin{array}{c}0.0036^{*} \\
(0.0022)\end{array}$ \\
\hline The first threshold & TP1 & $\begin{array}{c}0.1774^{* * *} \\
(0.0488)\end{array}$ & $\begin{array}{c}0.1790^{* * *} \\
(0.0488)\end{array}$ & $\begin{array}{c}0.1789^{* * *} \\
(0.0488)\end{array}$ \\
\hline The second threshold & TP2 & $\begin{array}{l}0.0597^{*} \\
(0.0380)\end{array}$ & $\begin{array}{l}0.0602^{*} \\
(0.0380)\end{array}$ & $\begin{array}{l}0.0602^{*} \\
(0.0379)\end{array}$ \\
\hline The third threshold & TP3 & $\begin{array}{c}0.3804^{* *} \\
(0.1826)\end{array}$ & $\begin{array}{c}0.3805^{* *} \\
(0.1825)\end{array}$ & $\begin{array}{c}0.3805^{* *} \\
(0.1825)\end{array}$ \\
\hline Threshold & TPS & $\begin{array}{l}0.5830 \\
0.8335\end{array}$ & $\begin{array}{l}0.5831 \\
0.8334\end{array}$ & $\begin{array}{l}0.5829 \\
0.8336\end{array}$ \\
\hline
\end{tabular}

Notes: The robust standard error against heteroscedasticity is in parentheses; ***, **, and ${ }^{*}$ present that the estimated coefficients are significant at the $1 \%, 5 \%$, and $10 \%$ confidence levels, respectively. 
Table 7 shows the results of panel threshold regression. The primary industry (fi), secondary industry (si), and tertiary industry (ti) are added to Models 5 7, respectively. GDP, real estate development investment (inv), per capita road paving area (road), and average wage of employees (wage) have a significant positive impact on the housing price. The primary industry has a negative impact on the housing price, the secondary industry has a negative but not significant impact on the housing price, and the tertiary industry has a significant positive impact on the housing price. The results are consistent with the ordinary panel regression model. The differences in the models used may cause slight changes, while some insignificant variables in the ordinary panel model have significant regression results in this model, indicating that the threshold panel model is closer to the actual fitting effect.

Specifically, the regression results show that the proportion of the primary industry in Model 5 is added as the control variable, and the two thresholds are 0.5830 and 0.8335 , respectively. The double threshold divides the impact of urbanization rate on housing price into three parts: The urbanization rate level is less than 0.5830 , that is, the region with a low urbanization rate; greater than 0.5830 but less than 0.8335 is the area with medium urbanization rate; and greater than 0.8335 is the region with a high level of urbanization. In the range of urbanization rate less than 0.5830 , the estimated coefficient of land finance is 0.1774 , that is, the price of commercial housing will rise by 0.1774 percentage points for each percentage point increase of land finance level. When the urbanization rate is greater than 0.5830 and less than 0.8335 , the estimated coefficient of land finance is 0.0597 . When the urbanization level is greater than 0.8335 , the estimated coefficient of land finance is 0.3804 . For every percentage point increase in land finance level, the price of commercial housing will increase by 0.3804 percentage points. Wu and $\mathrm{Cao}^{[46]}$ believed that with the continuous increase of urban population, a large number of rigid demands for housing will be created, but also resulting in generating investment demands for housing, which will enhance the rise of commercial housing prices. The empirical study shows that with the continuous improvement of urbanization level, the impact of land finance on the price of commercial housing presents a U-shaped feature, and thus Hypothesis 3 is verified. In areas with low and high urbanization levels, the positive effect of land finance on commodity housing price is greater, whereas in areas with medium urbanization level, the positive effect of land finance on commodity housing price is weaker. In the regression results for Model 6 and Model 7, thresholds do not change with the addition of new control variables. In a different threshold range, the land finance scale coefficient changes very slightly. For example, the scale coefficient of land finance in the low urbanization area changed from 0.5830 to 0.5831 and 0.5829 , respectively, and that in the high urbanization area changed from 0.8335 to 0.8334 and 0.8336 , respectively, indicating that the model results are robust.

\subsection{Results}

In the initial stage of urbanization to the medium level, with the expansion of the scale of land finance, the cost of expenditure includes land acquisition and demolition compensation expenditure, land transfer early development expenditure, subsidies for the land expropriated farmers, and so on. This aforementioned expenditure is the cost paid by the government in advance regarding the aspects of land acquisition, reserve, land consolidation, and so on, which paves the way for real estate. In this period, the expansion of land finance scale increased the 
public services in the region, and the increase of road paving area per capita, which represented the convenience of transportation, also enhanced the effect of the increase of housing price. The increase of average wages also led to the rise of housing prices, which substantiated the research conclusions of some scholars, that is, during the acceleration of urbanization and industrialization, the increase of demand for urban real estate caused by the increase of people's income is inevitable. During this period, investors' expectation of a promising prospect for the real estate market increased their speculation in the sector ${ }^{[4]}$. When the urbanization rate reaches the medium level, the increase in housing price is influenced by factors other than land finance, such as attracting more real estate development investment, and the higher housing supply reduces the driving effect of land finance on housing price. For example, some scholars have pointed out that housing price can be regarded as the cost of transferring from agricultural population to urban population, and housing price, to a certain extent, will hinder the urbanization process ${ }^{[4]}$. When urbanization reaches the developed stage, the income effect of housing price will emerge. With the increase of income and the improvement of cities, higher land finance will bring better supporting environment and facilities, which will have a more obvious effect on the increase of housing price. Black and Henderson ${ }^{[48]}$ found that urban agglomeration is characterized by high-end concentration, such as good education facilities are concentrated in metropolitan areas. In accordance with the law, non-cost land expenditure is used for government-subsidized housing projects, agriculture, rural areas, and urban and rural construction, which contribute to the benefits of shared land appreciation between urban and rural areas, increasing the attractiveness of real estate and housing price.

\section{Conclusions and Policy Implication}

\subsection{Conclusion}

This paper conducts an empirical study on the relationship between land finance scale and commodity housing price by constructing the regression model of ordinary panel and threshold panel. All the results demonstrate a positive relationship between land finance and the price of urban commercial housing. By comparing the four results of the ordinary panel regression model, it is observed that the impact of land finance on the price of commercial housing changes in quantity or direction, which indicates that the impact of land finance on housing price is regulated by the variable of urbanization rate, and the effect of land finance on housing price is heterogeneous with the difference of urbanization rate. According to the results of the threshold panel regression model, the impact of land finance on the housing price is different at different urbanization levels. There is a significant positive correlation between land finance and housing price, as well as a threshold effect of urbanization rate. With continuous improvement of the urbanization level, the impact of land finance scale on housing price presents a "U" shape. 
This study also ascertained that, comparing factors affecting the housing price, the development level of GDP in a region had the greatest promoting effect on the housing price, which was more than $60 \%$. This shows that the price rise of commercial housing is an economic phenomenon with the improvement of the economic development level. The rapidly developing economy will result in a rapid increase in housing prices. Conversely, if the economy declines, housing prices will follow suit.

In addition, the major factor affecting the housing price is the average income level of residents, which is more than $18 \%$. Because of the consumption patterns and the imbedded culture of China, besides getting married and starting a career, buying a house is the biggest consumption decision for a family. The increase of income will promote the rise of housing price, which indicates that housing price is a concomitant phenomenon of economic development, which shows that demand plays a major role in promoting housing price from another perspective. In addition, the real estate development investment also played a certain role in promoting the price of commercial housing, up to $17 \%$. Among the factors affecting the housing price selected in this paper, the industrial structure and population density are not significant, which warrant further studies in the future.

\subsection{Policy Suggestions}

\section{Persevere in economic development}

Housing price is a concomitant phenomenon of economic development. We should not attempt to reverse the procedure to restrain the rise of housing price and ignore the growth of economy. During the economic recession, the housing price will decrease, but at the same time, it will easily cause a comprehensive economic and financial crisis. The occurrence of housing bubble will also influence social stability and welfare improvement.

Positive role of land finance and reasonable use of land financial means to ease housing prices at different levels of urbanization

In the first period of urbanization development, the impact of land finance on the price of commercial housing is relatively moderate. The government can use the scale of land finance to adjust the housing price, but the single effect is not evident. Therefore, it is necessary to formulate a policy combination for joint regulation. When the urbanization level reaches the medium level, the government must actively make use of economic policies, monetary policies, and other policies to better promote the development of regional real estate industry. When the level of urbanization reaches a higher level, the government can actively utilize the land finance scale to effectively curb the regional housing price rise. The reason for the over-development of local real estate in this period is land finance. Weakening the land finance will optimize the local economy and local financial structure in this period. Land finance is not a long-term solution, and the government should concentrate its fiscal revenue on other tax sources, such as emerging industries.

\section{Control of housing prices for adequate housing on the supply side}

Land supply control is the most common and direct policy in the real estate market to adjust its supply, considering the supply side. All localities should accelerate the construction of institutional system of multiple agent supply, multiple way guarantee, and both rent and purchase. Targeted regulation and control should be implemented for different levels of demand 
for house purchases. For ordinary residents, the development of common housing should be based on reality. In the land supply adjustment, in addition to increasing land supply, the government should also take effective measures to solve the problem of land hoarding, to improve the effect of controlling the rise of housing prices. With the rapid development of China's real estate market in the new era, land policies must be combined with economic policies, monetary policies, and other policies to advance the development of China's real estate industry.

\section{Guide residents toward reasonable consumption}

With the development of economy, in the context of China's economic transformation and upgrading, there will be more emerging industries. The real estate market will return to rationality under the guideline of "not speculating on real estate." The government should guide resident's investment in the direction of emerging industries other than real estate. Additionally, China should encourage rental housing, activate the rental market, improve the development of the rental market, and dampen down the housing market with the development of the rental market. The government should encourage consumers to "rent before buying" and follow the "from small to large" housing consumption rule.

\section{References}

[1] Edward L. Glaeser, Joshua D. Gottlieb. The wealth of cities: Agglomeration economies and spatial equilibrium in the United States. Journal of Economic Literature, 2009, 47(4): 983-1028.

[2] Zhao Y J. Land finance in China: History, logic and choice. Urban Development Studies, 2014, 21(1): 1-13.

[3] Zheng S Q, Cao Y, Liu H Y. The value of a city and its house price: An empirical study across 35 Chinese cities. Urban Development Studies, 2008, 15(1): 133-136.

[4] Chen S Q, Zhu Y L. An empirical study on price of real estate and urbanization in China. On Economic Problems, 2008, 30(1): 47-49.

[5] Xie F Q, Huang J H. Urbanization and real estate market supply and demand: A test based on Chinese data. Shanghai Journal of Economics, 2013, 25(8): 115-123.

[6] Jiang S, Wang Z. Spatial econometric analysis of Chinese urbanization and changes of real estate prices. Science Research Management, 2014, 35(11): 163-170.

[7] An T F, Dou X. On land finance and real estate market regulation. Sub National Fiscal Research, 2011, 8(2): 8-13.

[8] Wang B, Gao B. An empirical analysis on land finance, promotion stimulation and housing prices. Nanjing Journal of Social Sciences, 2011, 22(5): 28-34.

[9] Wang M, Li Y G, Wang Y X. Land finance, housing prices fluctuation and gap between urban and rural consumption: A research based on panel data simultaneous equations. Industrial Economics Research, 2013, 12(5): 84-92.

[10] Wang R G, He J C. Study on the endogenous mechanism of urban land resources allocation and housing price dynamic change-building data models affecting housing prices from the perspective of supply and demand. Price: Theory \& Practice, 2019, 39(8): 60-63.

[11] Duan L F, Wei M. Study on the synchronized development of population urbanization and land urbanization. Contemporary Economic Management, 2019, 41(11): 45-51.

[12] Wang H, Zhou S J. The analysis of the "direct effect" and "indirect effect" of urbanization affects on real estate prices: Based on the dynamic spatial Durbin Model of prefecture-level cities. Nankai Economic Studies, 2017, 33(2): 5-24.

[13] Shan Z P. The effect of land policy on real estate market under the macro-control. Jilin University, 2013.

[14] Dong Z X, Liu Q Z. Empirical analysis of the relationship between urbanization development and real estate price in China. Statistics and Management, 2013, 28(5): 83-84.

[15] Wang L P. Empirical research on the influencing factors of the "robustness" of China's real estate price. Management World, 2013, 29(10): 184-185. 
[16] Wang X. Empirical research on the impact of urbanization on housing price. Times Finance, 2019, 40(27): 99-101.

[17] Guo K. The relationship between land financial dependence, fiscal income gap and housing price: A research based on provincial panel data. Economic Review, 2013, 34(2): 69-75.

[18] Du H Y, Ma Y K, An Y B. The impact of land policy on the relation between housing and land prices: Evidence from China. Quarterly Review of Economics and Finance, 2010, 51(1): 19-27.

[19] Li H, He F C. The empirical analysis of the impact of land finance and factor of urbanization on housing prices: Based -provincial panel data of the housing prices in China during 1999 and 2014. Price: Theory \& Practice, 2016, 36(9): 89-92.

[20] Li C G, Pan K. Land finance, urbanization and real estate development: An empirical study based on the Simultaneous Equation Model of panel data. Inquiry into Economic Issues, 2018, 39(6): 43-53.

[21] Liu Y C, Chen J Z. Land system, financing mode and industrialization with Chinese characteristics. China Industrial Economics, 2020, 41(3): 5-23.

[22] Shen Y, Liu H Y. Housing prices and economic fundamentals: A cross city analysis of China for 1995-2002. Economic Research Journal, 2004, 50(6): 78-86.

[23] Ren M R, Liu B. The relationship between housing price and urbanization - Empirical study based on provincial panel data. South China Journal of Economics, 2009, 27(2): 41-49.

[24] Luo Y M. The effect of urbanization on housing prices: Linear or nonlinear? - Empirical study based on four panel data regression models. Journal of Finance and Economics, 2011, 37(4): 135-144.

[25] Huang Y N, LI Y G, Wang M. Land finance, housing price fluctuation and economic growth — A study based on simultaneous equations of panel data. Inquiry into Economic Issues, 2017, 38(5): 31-37.

[26] Han Z L, Wang H W. Regional differences, urbanization and real estate prices-evidence from China's real estate market. Inquiry into Economic Issues, 2014, 35(2): 63-70.

[27] Yin S G, Song W X, Ma Z F, et al. Spatial differentiation and influencing factors analysis of housing prices in Nanjing: Based on geographically weignted regression model. Human Geography, 2008, 33(3): 68-77.

[28] Wu J, Gyourko J, Deng Y. Evaluating the risk of Chinese housing markets: What we know and what we need to know. China Economic Review, 2016, 27(39): 91-114.

[29] Nathanson C G, Zwick E. Arrested development: Theory and evidence of supply-side speculation in the housing market. The Journal of Finance, 2018, 73(6): 2587-2633.

[30] Garriga C, Hedlund A, Tang Y, et al. Rural-urban migration, structural transformation, and housing markets in China. National Bureau of Economic Research, 2017.

[31] Gong W J, Xu C H, Wang H B. How does urbanisation drive up China's housing prices? — Spatial econometrics analysis based on urbanization level decomposition. Inquiry into Economic Issues, 2019, 40(3): 63-76.

[32] Glaeser E L, Gyourko J. The Impact of zoning on housing affordability. Harvard Institute of Economic Research Working Papers, 2002, 8835.

[33] Glaeser E L, Ward B A. The causes and consequences of land use regulation: Evidence from Greater Boston. SSRN Electronic Journal, 2006, 12601.

[34] Zhu L. Analysis of the climbing price of real estate under "potential over-urbanization". Economics and Management, 2007, 22(7): 5-9.

[35] Zheng J E. Study on the effects of land supply mode and land supply amount on real estate price. Zhejiang University, 2008.

[36] Bai Z J, Yang Q Y. Land supply, housing price fluctuations and local government's probable posture. Reform, 2012, 25(11): 83-90.

[37] Rao G X, Ge Y. How to resolve the problem "land finance" in real estate. Journal of Business Economics, 2014, 34(1): 71-78.

[38] Tang Y F, Wu Q Q. Land finance and level of housing price. Economic Theory and Business Management, 2018, 38(3): 43-56.

[39] Zhu Q, Guo Z J, Wang Y F, et al. Land finance has no significant influence on housing prices in Hunan. Land \& Resources Herald, 2010, 7(11): 50-50.

[40] Lei G Q, Qian R F. Analysis of the impact of land finance on real estate development investment and commercial housing price - Empirical evidence from China's prefecture-level panel data. Finance \& Trade Economics, 2014, 35(10): 5-16. 
[41] Feng L. Research on the impact of "land finance" on the price change of commercial housing. Shanghai Academy of Social Science, 2018.

[42] Hoffmann R, Lee C G, Ramasamy B, et al. FDI and pollution: A granger causality test using panel data. Journal of International Development, 2005, 17(3): 311-317.

[43] Zhang S C, Li D K. Financial basis analysis of "The second housing reform" — From the perspective of the relationship between land finance and real estate price. Public Finance Research, 2010, 31(7): 5-11.

[44] Zhou B, Du L. "Land finance" and real estate price rise: Theoretical analysis and empirical research. Finance \& Trade Economics, 2010, 31(8): 109-116.

[45] Wu G L, Feng Q, Li P. Does local governments' budget deficit push up housing prices in China? China Economic Review, 2015, 26(35): 183-196.

[46] Wu Z H, Cao J M. Research on the influence of urbanization on real estate demand and housing price - Based on the panel data of the Pearl River Delta Economic Zone from 2005 to 2016. Price: Theory \& Practice, 2018, 38(10): 157-160.

[47] Xiong Y, He C. Are high housing prices hindering China's urbanization process? — From the perspective of household registration system and land supply. Jianghan Tribune, 2019, 62(8): 38-45.

[48] Black D, Henderson V. Spatial evolution of population and industry in the United States. American Economic Review, 1999, 89(2): 321-327. 